\title{
Relação metionina + cistina / lisina digestível para frangos de corte cobb ${ }^{1}$
}

\author{
Fernando de Castro Tavernari ${ }^{2}$, Luis Ernesto Paez Bernal ${ }^{3}$, Horacio Santiago Rostagno ${ }^{3}$, \\ Luiz Fernando Teixeira Albino ${ }^{3}$, Rodolfo Alves Vieira
}

\section{RESUMO}

Em vista da constante evolução do melhoramento genético de frangos de corte, torna-se necessária a determinação das exigências nutricionais dessas aves, para assegurar seu desempenho. Assim sendo, dois experimentos foram realizados, com o objetivo de avaliar diferentes relações de metionina + cistina / lisina digestível sobre o desempenho de frangos de corte, nas fases de 11 a 21 e 22 a 35 dias de idade. O delineamento experimental nas duas fases avaliadas foi o de blocos casualizados, em arranjo fatorial $2 x 5+2$, (2 sexos e 5 diferentes relações met+cis/lis digestível e um tratamento controle para cada sexo), com oito repetições de 23 e 20 aves (COBB 500) por unidade experimental, nas fases descritas. As dietas atenderam às exigências, exceto para metionina + cistina e lisina. Para evitar o excesso de lisina digestível, seu nível foi calculado para $97 \%$ do recomendado para todas as fases. O tratamento controle foi adequado em lisina e metionina + cistina. As relações metionina + cistina/lisina digestível, para máximo desempenho de frangos de corte, machos e fêmeas, respectivamente, são de 75,53 e 78,23\%, na fase de 11 a 21 dias, e 78,83 e 79,82\%, na fase de 22 a 35 dias.

Palavras-chave: desempenho, exigência, nutrição.

\section{ABSTRACT}

\section{Nutritional requirements of digestible methionine + cystine for cobb broilers}

The continual evolution of poultry breeding brings about the need to determine the nutritional requirements of these birds to ensure performance. Therefore, this study carried out two experiments to evaluate different methionine + cystine / digestible lysine ratios on the performance of broiler growing phases starter (11 - 21 days) and growth (22 - 35 days). The experiment evaluated the two phases using a randomized block design in a factorial arrangement $2 \times 5+2$, ( 2 sexes and 5 different Met + Cys / digestible Lys ratios and a control treatment for each sex) with 8 repetitions of 23 and 20 birds (COBB 500) per experimental unit in the two phases. The diets met the requirements except for methionine + cysteine and lysine. To avoid excess lysine, its level was calculated to be $95 \%$ of the recommended level for all phases. The control treatment was adequate in lysine and methionine + cystine. The methionine + cystine / digestible lysine ratios for maximum performance of male and female broiler chicks, respectively, are 75.53 and $78.23 \%$ in the phase 11 to 21 days and 78.83 and $79.82 \%$ in the phase 22 to 35 days.

Key words: performance, requirement, nutrition.

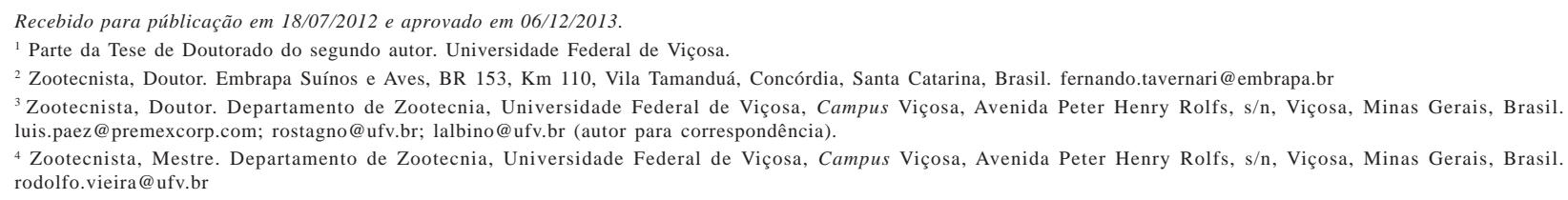




\section{INTRODUÇÃO}

O Brasil ocupa posição de destaque na produção de aves, estando entre os maiores produtores e exportadores de carne de frango. O contínuo progresso e a melhora do desempenho que apresenta a indústria avícola é produto da contribuição científica e tecnólogica de diferentes áreas. Obviamente, a nutrição está diretamente relacionada com este desenvolvimento e pode ser a área de maior impacto, na rentabilidade da produção, merecendo constante preocupação no sentido de atender, com precisão, às exigências nutricionais das aves. Assim sendo, têm-se buscado conhecer a composição nutricional e energética dos alimentos, bem como as exigências nutricionais das aves, e adotar o uso de formulações de dietas com base no conceito de aminoácidos digestíveis e de proteína ideal. É importante para o nutricionista dispor de informações atualizadas, para formular com precisão e poder cumprir o papel fundamental de reduzir os custos da alimentação, aliados à máxima produtividade das aves.

Os níveis ótimos de aminoácidos sulfurados, para a produção de carne de filé de peito, têm demonstrado serem maiores quando comparados com aqueles para peso da carcaça ou para ganho de peso (Hickling et al., 1990; Moran \& Bilgili, 1990; Holsheimer \& Veerkamp, 1992; Huyghebaert, 1993; Schutte \& Pack, 1995).

Dentre os aminoácidos essenciais, a metionina e a cistina são os primeiros aminoácidos limitantes, em rações para aves à base de milho e farelo de soja. Segundo Corzo (2004), de todos os aminoácidos, a cistina é a que mais contribui para a síntese de queratina, proteína que é a maior constituinte das penas, enquanto as propriedades da metionina, como principal doador de grupos metila, a tornam essencial para o crescimento.

Assim, objetivou-se, com este trabalho, determinar as exigências de metionina + cistina digestível, para frangos de corte machos e fêmeas, Cobb, nas diferentes fases de criação, e calcular as respectivas relações metionina + cistina digestível / lisina digestível e seus efeitos sobre os parâmetros de carcaça.

\section{MATERIAL E MÉTODOS}

Para a determinação das exigências nutricionais de metionina + cistina digestível, dois experimentos foram realizados no Setor de Avicultura do Departamento de Zootecnia da Universidade Federal de Viçosa (UFV), o primeiro foi relativo à fase inicial (de 11 a 21 dias) e, o segundo, à fase de crescimento (de 22 a 35 dias) de frangos de corte.

As aves foram alojadas em galpão de alvenaria e distribuídas em 96 boxes com dimensões de 1,0 x 2,25 m. Foi usada maravalha como material de cama e provido o aquecimento com lâmpadas de infravermelho. Durante todo o período experimental, as aves receberam ração farelada e água, "ad libitum", e foram criadas, seguindo as recomendações do Cobb Guía de Manejo de Pollo de engorde (Cobb, 2005).

No primeiro experimento (11 a 21 dias), foram utilizados 2208 frangos de corte da linhagem comercial Cobb 500 , machos e fêmeas. As aves foram distribuídas nos 96 boxes do galpão, em delineamento de blocos casualizados, e arranjo fatorial $6 \times 2$, sendo 5 relações de Met + Cis / Lis digestível $(64,68,72,76$ e 80\%) e 2 sexos (machos e fêmeas). Visando a evitar excesso de lisina digestível nestas dietas experimentais, o conteúdo utilizado foi de $97 \%$ do recomendado para esta fase, de acordo Rostagno et al. (2005). Os outros dois tratamentos (tratamentos 6 e 12, macho e fêmea respectivamente) foram rações controle contendo nível adequado de lisina $(1,160 \%)$ e Met + Cis $(0,928 \%=80 \%$ da lisina $)$. Desta forma, o experimento totalizou 12 tratamentos, com oito repetições de 23 aves por unidade experimental.

Para a obtenção das rações experimentais, inicialmente foram preparadas as rações correspondentes à relação de 64\% Met + Cis / Lis dig (tratamentos 1 e 7) e, posteriormente, a ração de $80 \%$ Met + Cis / Lis digestível foi obtida pela inclusão do aminoácido na forma industrial (DL Metionina), para atingir a relação de $80 \%$. Finalmente, as relações intermediárias $(68,72$ e $76 \%)$ foram obtidas pela mistura das rações extremas, ou seja, das relações de 64 e $80 \%$. A ração controle foi obtida pela inclusão de lisina e de metionina, nas quantidades faltantes para atingir os níveis previamente estabelecidos. Na Tabela 1, são apresentadas as rações experimentais (relação 64\% e dieta controle +).

No segundo experimento ( 22 a 35 dias), foram utilizados 1920 frangos de corte, da linhagem comercial Cobb 500, machos e fêmeas. As aves foram distribuídas nos 96 boxes do galpão, em delineamento de blocos casualizados, e arranjo fatorial 6 × 2, sendo 5 relações de Met + Cis/ Lis digestível (64, 68, 72, 76 e 80\%) e 2 sexos (machos e fêmeas). Com a finalidade de evitar excesso de lisina digestível, o conteúdo utilizado foi de $97 \%$ do recomendado por Rostagno et al. (2005). As rações controle (tratamentos 6 e 12, macho e fêmea, respectivamente) foram formuladas com nível adequado de lisina $(1,100 \%)$ e Met + Cis $(0,880 \%$ $=80 \%$ da lisina), para os machos (tratamento 6), e 1,040\% de lisina e $0,832 \%$ de Met + Cis ( $80 \%$ da lisina), para as fêmeas (tratamento 12). Desta forma, foram utilizados 12 tratamentos, com oito repetições de 20 aves por unidade experimental.

Para a obtenção das rações experimentais (diferenciadas para cada sexo), inicialmente foram preparadas as rações correspondentes à relação de $64 \%$ Met + Cis / Lis dig (tratamentos 1 e 7) e posteriormente a ração de $80 \%$ Met + Cis / Lis digestível foi obtida pela inclusão do 
aminoácido na forma industrial (DL Metionina), para atingir a relação de $80 \%$. Finalmente, as relações intermediárias $(68,72$ e $76 \%)$ foram obtidas pela mistura das rações

Tabela 1. Composição das rações experimentais para a determinação da exigência nutricional de Met +Cis em frangos de corte da linhagem COBB 500 na fase inicial (11-21 dias)

\begin{tabular}{|c|c|c|}
\hline Ingredientes, \% & Controle (+) & Trat. $(64 \%)$ \\
\hline Milho & 38,992 & 38,850 \\
\hline Farelo Soja (46\%) & 30,921 & 30,921 \\
\hline Sorgo Baixo Tanino & 20,000 & 20,000 \\
\hline F. glúten milho $(60 \%)$ & 4,000 & 4,000 \\
\hline Óleo & 1,928 & 1,928 \\
\hline F. bicálcico & 1,786 & 1,786 \\
\hline Calcário & 0,904 & 0,904 \\
\hline Sal & 0,483 & 0,483 \\
\hline DL-Metionina & 0,313 & 0,087 \\
\hline L-Lisina $\mathrm{HCl}$ & 0,278 & 0,202 \\
\hline L-Treonina & 0,042 & 0,042 \\
\hline Glicina & - & - \\
\hline L-Valina & - & - \\
\hline L-Arginina & - & - \\
\hline $\operatorname{Vit}^{1}+\operatorname{Min}^{2}+\operatorname{Aditivos}^{3}$ & 0,322 & 0,322 \\
\hline Amido & 0,031 & 0,333 \\
\hline Total & 100,00 & 100,00 \\
\hline \multicolumn{3}{|c|}{ Valores Calculados } \\
\hline Proteína bruta, \% & 21,5 & 21,5 \\
\hline Energia met, $\mathrm{kcal} / \mathrm{kg}$ & 3000,0 & 3000,0 \\
\hline $\mathrm{Ca}, \%$ & 0,884 & 0,884 \\
\hline P disponível, \% & 0,442 & 0,442 \\
\hline $\mathrm{Na}, \%$ & 0,214 & 0,214 \\
\hline Met. + Cis. dig, $\%$ & $0,928(80)^{4}$ & $0,704(64)$ \\
\hline Lisina dig, $\%$ & $1,160(100)$ & $1,100(100)$ \\
\hline Metionina dig, $\%$ & 0,633 & 0,409 \\
\hline Treonina dig, $\%$ & $0,759(65)$ & $0,758(69)$ \\
\hline Triptofano dig, $\%$ & $0,223(19)$ & $0,223(20)$ \\
\hline Arginina dig, $\%$ & $1,267(109)$ & $1,267(115)$ \\
\hline Valina dig, $\%$ & $0,926(80)$ & $0,926(84)$ \\
\hline Met. + Cis total, $\%$ & 1,007 & 0,783 \\
\hline Lisina total, $\%$ & 1,250 & 1,189 \\
\hline Metionina total, \% & 0,662 & 0,438 \\
\hline Treonina total, \% & 0,863 & 0,863 \\
\hline Triptofano total, $\%$ & 0,248 & 0,248 \\
\hline Arginina total, $\%$ & 1,329 & 1,329 \\
\hline Valina total, $\%$ & 1,033 & 1,032 \\
\hline Glicina+Serina total, $\%$ & 1,924 & 1,923 \\
\hline
\end{tabular}

${ }^{1}$ Níveis de garantia por quilo do produto: vit A - 10.000.000 UI; vit D3 - 2.000.000 UI; Vit E - 30.000 UI; Vit B1 - 2,0g; vit B6 - 4,0 g; Ac Pantotênico - 12,0g; Biotina - 0,10g; Vit K3 - 3,0 g ; Ácido fólico - 1,0 g; Ácido nicotínico - 50,0 g; Vit B12 - $15.000 \mathrm{mcg}$; Selênio - 0, $25 \mathrm{~g}$; e Veículo q. s. p - 1.000g.

${ }^{2}$ Níveis de garantia por quilo do produto: Manganês - 16,0 g; Ferro - 100,0 g; Zinco - 100,0 g; Cobre - 20,0 g; Cobalto - 2,0 g; Iodo $2,0 \mathrm{~g}$; e Veículo q. s. p. - 1.000g.

${ }^{3}$ Cloreto de Colina (70\%) e antioxidante (BHT).

${ }^{4}$ Valores de AAs Totais x Coef. Dig. das Tabelas Brasileiras, Rostagno et. al (2005). extremas, ou seja, das relações de 64 e $80 \%$. A ração controle foi obtida pela inclusão de lisina e de metionina nas quantidades faltantes para atingir os níveis previamente estabelecidos. Na Tabela 2, são apresentadas as rações experimentais (relação 64\% e dieta controle +).

As análises estatísticas foram realizadas pelo software Sistema de Análises Estatísticas e Genéticas (SAEG, 2007).

\section{RESULTADOS E DISCUSSÃO}

Na Tabela 3, são apresentados os resultados para o período inicial (11 a 21 dias de idade). Não houve efeito sobre o consumo de ração para os dois sexos, mostrando que as diferentes relações de Met + Cis / Lis digestível não influenciaram o consumo. Embora não tenha sido observado efeito sobre o consumo de ração, ao calcular o consumo de metionina + cistina, observa-se aumento do consumo do aminoácido de 6,658g a 7,865g, do tratamento com relação de $64,33 \%$, ao tratamento de $79,82 \%$, respectivamente, pelos machos e de $6,163 \mathrm{~g}$ a $7,148 \mathrm{~g}$ pelas fêmeas.

Foi observado efeito quadrático para ganho de peso $(\mathrm{P}<0,01)$ e conversão alimentar $(\mathrm{P}<0,01)$, pelos machos, o que corresponde a uma relação Met + Cis / Lis digestível de 75,38 e 75,67\% respectivamente, valores superiores à relação de 72\%, recomendada por Rostagno et al. (2011). Tomando-se o valor médio de lisina digestível analisada, de $1,060 \%$, determina-se que a exigência de metionina + cistina, para estas duas variáveis, é de 0,799 e 0,802\%, respectivamente, valores inferiores ao valor de exigência de $0,846 \%$, indicado também por Rostagno et al. (2011) para frangos machos de desempenho médio.

Houve efeito linear $(\mathrm{P}<0,01)$ para ganho de peso pelas fêmeas, correspondente à uma relação de $79,82 \%$, e um valor de exigência de metionina + cistina de $0,846 \%$. Para a conversão alimentar, foi observado efeito quadrático ( $\mathrm{P}<0,03)$, indicando uma relação de $76,63 \%$, e um valor de exigência de metionina + cistina de $0,812 \%$. Os resultados de conversão alimentar sugerem que níveis de metionina + cistina acima das exigências alteram o metabolismo, piorando o desempenho das aves. Resultados diferentes foram obtidos por Schutte \& Pack (1995), que verificaram que as necessidades em metionina + cistina, de frangos de corte, na fase de crescimento, para maximizar a eficiência de utilização do alimento, foi maior que as necessidades para maximizar o ganho de peso. Os autores sugeriram que esse fenômeno pode ser parcialmente explicado pelo fato de a metionina regular o consumo.

Atencio et al. (2004) observaram, em frangos machos Avian Farm ( de 1 a 20 dias de idade), efeito linear para ganho de peso e, quadrático, para conversão alimentar, sendo $79 \%$ a relação Met + Cis / Lis digestível para ganho de peso, correspondente a um valor de exigência para metionina + cistina de $0,916 \%$, valor este superior ao de- 
terminado neste experimento; contudo, o nível de lisina digestível utilizado pelos autores foi de $1,16 \%$, superior em 8,62\% ao nível usado para esta fase. Para conversão alimentar, os autores determinaram uma exigência de $0,876 \%$ de metionina + cistina digestível, pelo modelo quadrático, correspondente a uma relação de 75,5\%, que é praticamente igual à relação de 75,67\% estimada para este experimento, mas superior à recomendada por Baker \& Han (1994) e Rostagno et al. (2011) de 72\%. Albino et al. (1999) determinaram exigências, para máximo desem- penho, de 0,886 e 0,890\%, para frangos machos Hubbard e Cobb, respectivamente, na fase de 1 a 21 dias.

De acordo com o Cobb Broiler Nutrition Guide (Cobb, 2003), recomenda-se, para a fase inicial, uma relação Met + Cis / Lis digestível de 73,5\%, valor inferior aos 75,38 e $75,67 \%$ estimados para ganho e conversão. Essa relação corresponde a um nível de metionina + cistina digestível de $0,86 \%$, superior aos aqui determinados para ganho e conversão alimentar. O nível de lisina digestível recomendado pelo manual da linhagem é de 1,17\%.

Tabela 2. Composição das rações experimentais na fase de crescimento (22-35 dias)

\begin{tabular}{|c|c|c|c|c|}
\hline \multirow{2}{*}{ Ingredientes, \% } & Controle (+) & Trat $(64 \%)$ & Controle (+) & Trat $(64 \%)$ \\
\hline & \multicolumn{2}{|c|}{ Machos } & \multicolumn{2}{|c|}{ Fêmeas } \\
\hline Milho & 38,910 & 38,910 & 42,700 & 42,700 \\
\hline Farelo Soja (46\%) & 32,902 & 32,902 & 30,004 & 30,004 \\
\hline Sorgo Baixo Tanino & 20,000 & 20,000 & 20,000 & 20,000 \\
\hline Óleo & 4,330 & 4,330 & 3,570 & 3,570 \\
\hline F. bicálcico & 1,634 & 1,634 & 1,538 & 1,538 \\
\hline Calcário & 0,838 & 0,838 & 0,804 & 0,804 \\
\hline Sal & 0,461 & 0,461 & 0,435 & 0,435 \\
\hline DL-Metionina & 0,336 & 0,113 & 0,307 & 0,094 \\
\hline L-Lisina $\mathrm{HCl}$ & 0,184 & 0,095 & 0,192 & 0,103 \\
\hline L-Treonina & 0,025 & 0,025 & 0,041 & 0,041 \\
\hline L-Valina & 0,027 & 0,027 & 0,020 & 0,020 \\
\hline $\operatorname{Vit}^{1}+\operatorname{Min}^{2}+\operatorname{Aditivos}^{3}$ & 0,320 & 0,320 & 0,320 & 0,320 \\
\hline Amido & 0,033 & 0,345 & 0,069 & 0,371 \\
\hline Total & 100,000 & 100,000 & 100,000 & 100,000 \\
\hline \multicolumn{5}{|l|}{ Valores Calculados } \\
\hline Proteína bruta, \% & 20,0 & 20,0 & 19,0 & 19,0 \\
\hline Energia met, $\mathrm{kcal} / \mathrm{kg}$ & 3100,0 & 3100,0 & 3100,0 & 3100,0 \\
\hline $\mathrm{Ca}, \%$ & 0,824 & 0,824 & 0,781 & 0,781 \\
\hline P disponível, \% & 0,411 & 0,411 & 0,391 & 0,391 \\
\hline $\mathrm{Na}, \%$ & 0,205 & 0,205 & 0,195 & 0,195 \\
\hline Met. + Cis. dig, $\%$ & $0,880(80)^{4}$ & $0,659(64)$ & $0,832(80)$ & $0,621(64)$ \\
\hline Lisina dig, $\%$ & $1,100(100)$ & $1,030(100)$ & $1,040(100)$ & $0,970(100)$ \\
\hline Metionina dig, $\%$ & 0,612 & 0,391 & 0,572 & 0,361 \\
\hline Treonina dig, \% & $0,700(64)$ & $0,700(68)$ & $0,676(65)$ & $0,676(70)$ \\
\hline Triptofano dig, $\%$ & $0,224(20)$ & $0,224(22)$ & $0,210(20)$ & $0,210(22)$ \\
\hline Arginina dig, $\%$ & $1,255(114)$ & $1,255(122)$ & $1,176(113)$ & $1,176(121)$ \\
\hline Valina dig, $\%$ & $0,882(80)$ & $0,882(86)$ & $0,832(80)$ & $0,832(86)$ \\
\hline Met. + Cis total, $\%$ & 0,955 & 0,734 & 0,903 & 0,692 \\
\hline Lisina total, $\%$ & 1,190 & 1,120 & 1,125 & 1,055 \\
\hline Metionina total, $\%$ & 0,639 & 0,419 & 0,599 & 0,388 \\
\hline Treonina total, $\%$ & 0,797 & 0,797 & 0,773 & 0,773 \\
\hline Triptofano total, $\%$ & 0,249 & 0,249 & 0,234 & 0,234 \\
\hline Arginina total, $\%$ & 1,317 & 1,317 & 1,236 & 1,236 \\
\hline Valina total, $\%$ & 0,987 & 0,987 & 0,933 & 0,933 \\
\hline Gli+Ser total, \% & 1,811 & 1,811 & 1,717 & 1,717 \\
\hline
\end{tabular}

${ }^{1}$ Níveis de garantia por quilo do produto: vit A - 10.000.000 UI; vit D3 - 2.000.000 UI; Vit E - 30.000 UI; Vit B1 - 2,0g; vit B6 - 4,0 g; Ac Pantotênico - 12,0g; Biotina - 0,10g; Vit K3 - 3,0 g ; Ácido fólico - $1,0 \mathrm{~g}$; Ácido nicotínico - 50,0 g ; Vit B12 - 15.000 mcg ; Selênio - 0, 25 g; e Veículo q. s. p - 1.000g.

${ }^{2}$ Níveis de garantia por quilo do produto: Manganês - 16,0 g; Ferro - 100,0 g; Zinco - 100,0 g; Cobre - 20,0 g; Cobalto - 2,0 g; Iodo - 2,0 g; e Veículo q. s. p. - 1.000g.

${ }^{3}$ Cloreto de Colina (70\%) e antioxidante (BHT).

${ }^{4}$ Valores de AAs Totais x Coef. Dig. das Tabelas Brasileiras, Rostagno et. al (2005). 
Junior et al. (2006), estudando a exigência de metionina + cistina para frangos de corte fêmeas Ross, no período de 1 a 21 dias de idade, observaram efeito quadrático sobre o ganho de peso, estimando-se a exigência em 0,8713\% de metionina + cistina digestível, correspondente a uma relação de 73,84 \%. Esta relação é inferior à relação de $79,82 \%$, dado que o efeito dos níveis de metionina + cistina foi linear. Sobre a conversão alimentar, constatou-se efeito quadrático dos níveis de metionina + cistina, estimando-se, igual para ganho de peso, em $0,8713 \%$ o nível de metionina + cistina digestível na ração, para a melhor eficiência alimentar das aves, valor superior em $6,8 \%$ ao estimado neste experimento.

Tabela 3. Efeito da relação Met + Cis / Lis digestível sobre o desempenho de frangos de corte machos e fêmeas, na fase inicial (1121 dias de idade)

\begin{tabular}{|c|c|c|c|c|c|c|}
\hline \multirow{2}{*}{ Met+cis/lis (\%) } & \multicolumn{2}{|c|}{ Ganho de Peso (g) } & \multicolumn{2}{|c|}{ Consumo de Ração (g) } & \multicolumn{2}{|c|}{ Conversão Alimentar } \\
\hline & Machos & Fêmeas & Machos & Fêmeas & Machos & Fêmeas \\
\hline 64,33 & $555^{*}$ & 498 & 822 & 761 & $1,483^{*}$ & $1,528^{*}$ \\
\hline 70,47 & 573 & 498 & 819 & 748 & 1,429 & $1,502^{*}$ \\
\hline 72,09 & 578 & 506 & 833 & 752 & 1,442 & 1,485 \\
\hline 76,08 & $565^{*}$ & 504 & 810 & 749 & 1,434 & 1,485 \\
\hline 79,82 & 575 & 504 & 825 & 750 & 1,434 & 1,488 \\
\hline Média & $569^{\mathrm{A}}$ & $502^{\mathrm{B}}$ & $822^{\mathrm{A}}$ & $752^{\mathrm{B}}$ & $1,444^{\mathrm{B}}$ & $1,498^{\mathrm{A}}$ \\
\hline Controle (+) & 582 & 501 & 832 & 740 & 1,431 & 1,477 \\
\hline Regressão & $\mathrm{Q}^{1}$ & $\mathrm{~L}^{2}$ & $\mathrm{~ns}^{3}$ & ns & $\mathrm{Q}^{4}$ & $\mathrm{Q}^{5}$ \\
\hline Met+cis/lis (\%) & 75,38 & 79,82 & - & - & 75,67 & 76,63 \\
\hline$\overline{\mathrm{CV}(\%)}$ & 1,125 & 1,796 & 1,740 & & & \\
\hline \multicolumn{7}{|c|}{ 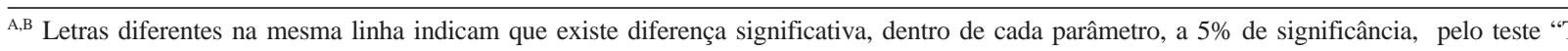 } \\
\hline \multicolumn{7}{|c|}{ * Médias com asterisco diferem $(\mathrm{P}<0,05)$ do Controle $(+)$ pelo teste de Dunnett. } \\
\hline \multicolumn{7}{|c|}{${ }^{1}$ Efeito quadrático: $\mathrm{Y}=-257,462+22,0655 \mathrm{X}-0,146349 \mathrm{X}^{2} ; \mathrm{R}^{2}=0,51(\mathrm{P}<0,01)$} \\
\hline \multicolumn{7}{|c|}{${ }^{2}$ Efeito linear: $\mathrm{Y}=470,956+0,428281 \mathrm{X} ; \mathrm{R}^{2}=0,53(\mathrm{P}<0,01)$} \\
\hline \multicolumn{7}{|c|}{${ }^{3}$ Não significativo. } \\
\hline \multicolumn{7}{|c|}{${ }^{4}$ Efeito quadrático: $\mathrm{Y}=3,70212-0,060064 \mathrm{X}+0,00039687 \mathrm{X}^{2} ; \mathrm{R}^{2}=0,72(\mathrm{P}<0,01)$} \\
\hline${ }^{5}$ Efeito quadrático: & (2) & & & & & \\
\hline
\end{tabular}

Tabela 4. Efeito da relação Met + Cis / Lis digestível sobre o desempenho de frangos de corte machos e fêmeas, na fase de crescimento (22-35 dias de idade)

\begin{tabular}{|c|c|c|c|c|c|c|}
\hline \multirow{2}{*}{$\begin{array}{l}\text { Met+cis/lis (\%) } \\
\text { M / F }\end{array}$} & \multicolumn{2}{|c|}{ Ganho de Peso (g) } & \multicolumn{2}{|c|}{ Consumo de Ração (g) } & \multicolumn{2}{|c|}{ Conversão Alimentar } \\
\hline & Machos & Fêmeas & Machos & Fêmeas & Machos & Fêmeas \\
\hline $64,09 / 65,74$ & 1097 & 881 & 1958 & 1720 & $1,788^{*}$ & $1,956^{*}$ \\
\hline $66,75 / 72,10$ & 1138 & 892 & 1982 & 1696 & $1,742^{*}$ & $1,903^{*}$ \\
\hline $72,07 / 73,46$ & 1150 & 889 & 1940 & 1653 & 1,690 & 1,858 \\
\hline $77,74 / 80,65$ & 1133 & 900 & 1912 & 1669 & 1,690 & 1,854 \\
\hline $79,61 / 83,12$ & 1163 & 903 & 1960 & 1665 & 1,689 & 1,847 \\
\hline Média & $1136^{\mathrm{A}}$ & $893^{\text {B }}$ & $1950^{\mathrm{A}}$ & $1680^{\mathrm{B}}$ & $1,720^{\mathrm{B}}$ & $1,884^{\mathrm{A}}$ \\
\hline Controle (+) & 1151 & 906 & 1912 & 1659 & 1,665 & 1,831 \\
\hline Regressão & $\mathrm{L}^{1}$ & $\mathrm{~ns}^{2}$ & ns & $\mathrm{Q}^{3}$ & $\mathrm{Q}^{4}$ & $\mathrm{Q}^{5}$ \\
\hline Met+cis/lis (\%) & 79,61 & - & - & 78,90 & 75,73 & 81,45 \\
\hline $\mathrm{CV}(\%)$ & 2,35 & 1,93 & 1,61 & & & \\
\hline \multicolumn{7}{|c|}{ A,B Letras diferentes na mesma linha indicam que existe diferença significativa, dentro de cada parâmetro, a 5\% de significância, pelo teste " } \\
\hline \multicolumn{7}{|c|}{ * Médias com asterisco diferem $(\mathrm{P}<0,05)$ do Controle $(+)$ pelo teste de Dunnett. } \\
\hline \multicolumn{7}{|c|}{${ }^{1}$ Efeito linear: $\mathrm{Y}=941,742+2,69924 \mathrm{X} ; \mathrm{R}^{2}=0,65(\mathrm{P}<0,01)$} \\
\hline \multicolumn{7}{|c|}{${ }^{2}$ Não significativo. } \\
\hline \multicolumn{7}{|c|}{${ }^{3}$ Efeito quadrático: $\mathrm{Y}=3,81106-0,0544816 \mathrm{X}+0,000345223 \mathrm{X}^{2} ; \mathrm{R}^{2}=0,88(\mathrm{P}<0,03)$. } \\
\hline \multicolumn{7}{|c|}{${ }^{4}$ Efeito quadrático: $\mathrm{Y}=6,14248-0,117824 \mathrm{X}+0,000777924 \mathrm{X}^{2} ; \mathrm{R}^{2}=0,92(\mathrm{P}<0,01)$} \\
\hline${ }^{5}$ Efeito quadrático: & & $22 \mathrm{X}+0,00$ & $9 \mathrm{X}^{2} ; \mathrm{R}^{2}=0$, & $0,01)$. & & \\
\hline
\end{tabular}


Os resultados de ganho de peso, consumo de ração e conversão alimentar, para a fase de 22 a 35 dias, são apresentados na Tabela 4.

Foi observado efeito linear para o ganho de peso $(\mathrm{P}<0,01)$ e efeito quadrático para a conversão alimentar $(\mathrm{P}<0,01)$, pelos machos, o que corresponde a uma relação Met + Cis / Lis digestível de 79,61 e 75,73\%, respectivamente. Tomando-se o valor médio de lisina digestível analisado, de 0,992\%, determina-se que a exigência de metionina + cistina, para estas duas variáveis é de 0,790 e $0,751 \%$, respectivamente. O valor de exigência para ganho de peso pelos machos, determinado neste experimento, resulta muito próximo do valor estimado por Albino et al. (1999), de 0,782\%, para machos Hubbard, no período de 22 a 42 dias. Atencio et al. (2004) determinaram, para ganho de peso em machos Avian, uma exigência de 0,827 de metionina + cistina digestível, pelo método quadrático, e $0,767 \%$, pelo modelo descontínuo, valores que correspondem a relações de metionina + cistina / lisina digestível de 77,2 e 72\%, respectivamente; sendo ambas as relações inferiores àquela determinada neste experimento, dado o efeito linear dos níveis crescentes de metionina + cistina, neste experimento. Entretanto, como se pode observar, os níveis de exigência de metionina + cistina, determinados por Atencio et al. (2004), por meio dos dois modelos, são ainda superiores, sendo que o nível de lisina digestível usado por Atencio et al. (2004) foi de $1,065 \%$; entretanto, para este experimento foi de $0,992 \%$.

Para a conversão alimentar, a relação metionina + cistina / lisina digestível de 75,73\% é ligeiramente superior à rela- ção de 75\%, recomendada por Parsons \& Baker (1994) e Mack et al. (1999). Observa-se também que o valor de exigência dos machos, para conversão alimentar, foi inferior ao valor para ganho de peso, o que está em concordância com o achado por Albino et al. (1999), que determinaram valores de exigência de metionina + cistina total, para conversão alimentar, de 0,814 e 0,781\%, para machos e fêmeas Ross, respectivamente, no período de 22 a 42 dias de idade.

Para as fêmeas, não foi observado efeito significativo dos níveis de metionina + cistina sobre o ganho de peso. No entanto, para o parâmetro de conversão alimentar, houve efeito quadrático, estimando-se uma relação de $81,45 \%$ de Met + Cis / Lis digestível, correspondente a uma exigência de $0,723 \%$ de metionina + cistina.

A estimativa da exigência para conversão alimentar ficou abaixo do nível de $0,885 \%$, encontrado por Junior $e t$ al. (2006), ao estudarem o efeito de níveis de metionina + cistina, para frangos de corte fêmeas da marca comercial Ross, no período de 22 a 42 dias de idade. Os autores também observaram efeito quadrático dos níveis de metionina + cistina sobre o parâmetro de conversão alimentar, estabelecendo uma relação de $82,05 \%$, valor próximo ao aqui determinado.

O Cobb Broiler Nutrition Guide (Cobb, 2003) recomenda, para o período de crescimento, uma relação Met + Cis / Lis digestível de 76,4\%, valor levemente superior ao estimado para melhor conversão alimentar, pelos machos, que foi de $75,73 \%$ e inferior aos $79,61 \%$, para ganho de peso pelos machos, e $81,45 \%$ estimados para conversão pelas fêmeas. No entanto, a relação do ma-

Tabela 5. Efeito da relação Met + Cis / Lis digestível sobre os parâmetros de carcaça (g) de frangos de corte machos e fêmeas aos 35 dias de idade

\begin{tabular}{|c|c|c|c|c|c|c|}
\hline \multirow{2}{*}{$\begin{array}{l}\text { Met+cis/lis (\%) } \\
\text { M / F }\end{array}$} & \multicolumn{2}{|c|}{ Carcaça (g) } & \multicolumn{2}{|c|}{ Gordura (g) } & \multicolumn{2}{|c|}{ Coxa-Sobrecoxa (g) } \\
\hline & Machos & Fêmeas & Machos & Fêmeas & Machos & Fêmeas \\
\hline $64,1 / 65,7$ & 1298 & 1095 & 20 & $22^{*}$ & 381 & 309 \\
\hline $66,7 / 72,1$ & 1332 & 1113 & 17 & $19^{*}$ & 388 & 314 \\
\hline $72,1 / 73,5$ & 1337 & 1120 & 19 & 16 & 383 & 318 \\
\hline $77,7 / 80,6$ & 1317 & 1121 & 20 & 17 & 385 & 314 \\
\hline $79,6 / 83,1$ & 1356 & 1135 & 17 & $18^{*}$ & 388 & 323 \\
\hline Média & $1328^{\mathrm{A}}$ & $1117^{\mathrm{B}}$ & 18 & 19 & $385^{\mathrm{A}}$ & $315^{\mathrm{B}}$ \\
\hline Controle (+) & 1348 & 1135 & 16 & 15 & 397 & 325 \\
\hline Regressão & $\mathrm{L}^{1}$ & $\mathrm{~L}^{2}$ & $\mathrm{~ns}^{3}$ & $\mathrm{Q}^{4}$ & ns & $\mathrm{L}^{5}$ \\
\hline Met+cis/lis (\%) & 79,60 & 83,12 & $\longrightarrow$ & 77,14 & $\longrightarrow$ & 83,10 \\
\hline $\mathrm{CV}(\%)$ & 2,41 & 20,12 & 3,65 & & & \\
\hline \multicolumn{7}{|c|}{ A,B Letras diferentes na mesma linha indicam que existe diferença significativa, dentro de cada parâmetro, a 5\% significância, pelo teste " $\mathrm{T}$} \\
\hline \multicolumn{7}{|c|}{ * Médias com asterisco diferem $(\mathrm{P}<0,05)$ do Controle $(+)$ pelo teste de Dunnett. } \\
\hline \multicolumn{7}{|c|}{${ }^{1}$ Efeito linear: $\mathrm{Y}=1183,59+2,00364 \mathrm{X} ; \mathrm{R}^{2}=0,54(\mathrm{P}<0,01)$} \\
\hline \multicolumn{7}{|c|}{${ }^{2}$ Efeito linear: $\mathrm{Y}=969,254+1,96634 \mathrm{X} ; \mathrm{R}^{2}=0,91(\mathrm{P}<0,01)$} \\
\hline \multicolumn{7}{|c|}{${ }^{3}$ Não significativo. } \\
\hline \multicolumn{7}{|c|}{${ }^{4}$ Efeito quadrático: $\mathrm{Y}=264,569-6,42783 \mathrm{X}+0,0416655 \mathrm{X}^{2} ; \mathrm{R}^{2}=0,92(\mathrm{P}<0,01)$} \\
\hline${ }^{5}$ Efeito linear: $\mathrm{Y}=$ & $270,746+0,5$ & $\mathrm{R}^{2}=0,70$ & & & & \\
\hline
\end{tabular}

Rev. Ceres, Viçosa, v. 61, n.2, p. 193-201, mar/abr, 2014 
nual Cobb corresponde a um nível de metionina + cistina digestível de $0,84 \%$, valor superior aos aqui determinados para ganho $(0,789 \%)$ e conversão alimentar $(0,751 \%)$, pelos machos. O nível de lisina digestível recomendado pelo manual da linhagem para esta fase é de $1,10 \%$.

Rostagno et al. (2011) recomendam, para machos de desempenho médio, na fase de 22 a 33 dias de idade, uma relação de $73 \%$ e uma exigência de metionina + cistina de $0,787 \%$, sendo que, desses valores, o da relação é inferior ao $75,73 \%$, estimado para melhor conversão alimentar pelos machos e, no entanto, o nível de exigência, está próximo aos estimados para ganho $(0,789 \%)$ e conversão alimentar $(0,751 \%)$. Para as fêmeas de desempenho médio, os autores recomendam relação de $72 \%$, bem menor que a relação de $81,45 \%$ obtida para esta fase, e uma exigência de metionina + cistina de $0,718 \%$, nível que é próximo ao valor de $0,722 \%$.

Os dados da carcaça, cortes e rendimentos, obtidos na fase de crescimento (22 a 35 dias) são apresentados nas Tabelas 5, 6, 7 e 8.

Os resultados dos parâmetros de peso de carcaça e de cortes, avaliados, mostram que houve efeito linear dos níveis de metionina + cistina digestível sobre o peso de carcaça $(\mathrm{P}<0,01)$ e peso do peito $(\mathrm{P}<0,01)$, tanto para os machos como para as fêmeas. Também foi observado o mesmo efeito linear sobre o peso do filé, para os machos, e peso de coxa-sobrecoxa, para as fêmeas, o que corresponde a uma relação de $79,6 \%$, para os machos, e $83,1 \%$, para as fêmeas, valores que resultam maiores quando comparados com os da relação Met + Cis / Lis digestível, determinados para melhor conversão alimentar para os dois sexos (75,73 e 81,45\%), indicando, assim, que existe uma exigência maior para máximo peso de corte. Para as variáveis de peso da gordura e peso do filé, para as fêmeas, houve efeito de tipo quadrático $(\mathrm{P}<0,01 \mathrm{e}$ $\mathrm{P}<0,05)$, o que corresponde a uma relação de 77,14 e $80,02 \%$, respectivamente.

Com relação aos parâmetros de rendimentos de carcaça, gordura, coxa-sobrecoxa, peito e filé, para os machos, não foi observado efeito significativo dos níveis de metionina + cistina digestível, indicando, estatisticamente, para o rendimento dos machos, na fase de 22 a 35 dias, a relação de $64,1 \%$. Estes resultados diferem dos obtidos por Rodrigueiro et al. (2000) e Junior et al. (2005), que observaram efeito quadrático e linear, respectivamente, sobre o rendimento de carcaça, estimando exigência de 0,814 e $0,864 \%$ de metionina + cistina total, $(0,780 \%$ lis digestível).

Entretanto, as fêmeas apresentaram resposta quadrática para as variáveis de rendimento de gordura $(78,89 \%)$, peito $(75,22 \%)$ e filé $(77,29 \%)$, valores que correspondem a níveis de exigência de metionina + cistina digestível de $0,699,0,667$ e $0,686 \%$ respectivamente. Os valores aqui obtidos para as fêmeas indicam que o nível de exigência de metionina + cistina, para menor deposição de gordura, é maior do que os valores dos níveis de exigências para rendimento de filé e peito, respectivamente. Do mesmo modo, estes valores de exigência para as variáveis de rendimento, para as fêmeas, são superiores aos valores de exigência para máximo ganho de peso e melhor conversão alimentar.

Tabela 6. Efeito da relação Met + Cis / Lis digestível sobre os parâmetros de carcaça (g) de frangos de corte machos e fêmeas aos 35 dias de idade

\begin{tabular}{|c|c|c|c|c|}
\hline \multirow{2}{*}{$\begin{array}{l}\text { Met+cis/lis (\%) } \\
\text { M / F }\end{array}$} & \multicolumn{2}{|c|}{ Peito (g) } & \multicolumn{2}{|c|}{ Filé de peito $(g)$} \\
\hline & Machos & Fêmeas & Machos & Fêmeas \\
\hline $64,1 / 65,7$ & 420 & 348 & $308^{*}$ & $254^{*}$ \\
\hline $66,7 / 72,1$ & 434 & 363 & 322 & $264^{*}$ \\
\hline $72,1 / 73,5$ & 439 & 367 & 322 & 271 \\
\hline $77,7 / 80,6$ & 430 & 363 & $319^{*}$ & 273 \\
\hline $79,6 / 83,1$ & 442 & 366 & 330 & 272 \\
\hline Média & $433^{\mathrm{A}}$ & $361^{\mathrm{B}}$ & $320^{\mathrm{A}}$ & $267^{\mathrm{B}}$ \\
\hline Controle (+) & 445 & 372 & 328 & 278 \\
\hline Regressão & $\mathrm{L}^{1}$ & $\mathrm{~L}^{2}$ & $\mathrm{~L}^{3}$ & $\mathrm{Q}^{4}$ \\
\hline Met+cis/lis (\%) & 79,60 & 83,10 & 79,60 & 80,02 \\
\hline $\mathrm{CV}(\%)$ & 3,40 & 3,61 & & \\
\hline \multicolumn{5}{|c|}{ A,B Letras diferentes na mesma linha indicam que existe diferença significativa, dentro de cada parâmetro, a 5\% significância , pelo teste "T". } \\
\hline \multicolumn{5}{|c|}{ * Médias com asterisco diferem $(\mathrm{P}<0,05)$ do Controle $(+)$ pelo teste de Dunnett. } \\
\hline \multicolumn{5}{|c|}{${ }^{1}$ Efeito linear: $\mathrm{Y}=373,885+0,818940 \mathrm{X} ; \mathrm{R}^{2}=053(\mathrm{P}<0,01)$} \\
\hline \multicolumn{5}{|c|}{${ }^{2}$ Efeito linear: $\mathrm{Y}=298,275+0,841844 \mathrm{X} ; \mathrm{R}^{2}=0,56(\mathrm{P}<0,01)$} \\
\hline \multicolumn{5}{|c|}{${ }^{3}$ Efeito linear: $\mathrm{Y}=256,690+0,881106 \mathrm{X} ; \mathrm{R}^{2}=0,70(\mathrm{P}<0,05)$} \\
\hline \multicolumn{5}{|c|}{${ }^{4}$ Efeito quadrático: $\mathrm{Y}=-339,412+15,2964 \mathrm{X}-0,0955762 \mathrm{X}^{2} ; \mathrm{R}^{2}=0,99(\mathrm{P}<0,05)$} \\
\hline
\end{tabular}


Tabela 7. Efeito da relação Met + Cis / Lis digestível sobre os parâmetros de rendimento carcaça de frangos de corte machos e fêmeas aos 35 dias de idade

\begin{tabular}{|c|c|c|c|c|c|c|}
\hline \multirow{2}{*}{$\begin{array}{l}\text { Met+cis/lis (\%) } \\
\text { M / F }\end{array}$} & \multicolumn{2}{|c|}{ Carcaça (\%) } & \multicolumn{2}{|c|}{ Gordura (\%) } & \multicolumn{2}{|c|}{ Coxa-Sobrecoxa $(\%)$} \\
\hline & Machos & Fêmeas & Machos & Fêmeas & Machos & Fêmeas \\
\hline $64,1 / 65,7$ & 70,33 & 70,77 & 1,51 & $1,98^{*}$ & 29,36 & 28,19 \\
\hline $66,7 / 72,1$ & 70,38 & 71,42 & 1,25 & $1,74^{*}$ & 29,15 & 28,18 \\
\hline $72,1 / 73,5$ & 70,07 & 72,04 & 1,40 & 1,41 & 28,63 & 28,39 \\
\hline $77,7 / 80,6$ & 70,25 & 71,65 & 1,52 & 1,51 & 29,22 & 27,96 \\
\hline $79,6 / 83,1$ & 71,09 & 71,93 & 1,24 & $1,62^{*}$ & 28,64 & 28,45 \\
\hline Média & 70,42 & 71,56 & 1,38 & 1,65 & 29,00 & 28,23 \\
\hline Controle $(+)$ & 71,01 & 72,21 & 1,15 & 1,31 & 29,44 & 28,61 \\
\hline Regressão & $\mathrm{ns}^{1}$ & ns & ns & $\mathrm{Q}^{2}$ & ns & ns \\
\hline Met+cis/lis (\%) & - & - & - & 78,89 & - & - \\
\hline $\mathrm{CV}(\%)$ & 2,09 & 19,48 & 2,95 & & & \\
\hline
\end{tabular}

Tabela 8. Efeito da relação Met + Cis / Lis digestível sobre os parâmetros de rendimento de carcaça (\%) de frangos de corte machos e fêmeas aos 35 dias de idade

\begin{tabular}{|c|c|c|c|c|}
\hline \multirow{2}{*}{$\begin{array}{l}\text { Met+cis/lis (\%) } \\
\text { M / F }\end{array}$} & \multicolumn{2}{|c|}{ Peito (\%) } & \multicolumn{2}{|c|}{ Filé de peito $(\%)$} \\
\hline & Machos & Fêmeas & Machos & Fêmeas \\
\hline $64,1 / 65,7$ & 32,34 & 31,76 & 23,74 & 23,18 \\
\hline $66,7 / 72,1$ & 32,56 & 32,58 & 24,14 & 23,66 \\
\hline $72,1 / 73,5$ & 32,86 & 32,81 & 24,05 & 24,24 \\
\hline 77,7 / 80,6 & 32,62 & 32,40 & 24,26 & 24,33 \\
\hline 79,6 / 83,1 & 32,62 & 32,27 & 24,38 & 23,92 \\
\hline Média & 32,60 & 32,36 & 24,11 & 23,86 \\
\hline Controle (+) & 32,99 & 32,78 & 24,33 & 24,48 \\
\hline Regressão & $\mathrm{ns}^{1}$ & $\mathrm{Q}^{2}$ & ns & $\mathrm{Q}^{3}$ \\
\hline Met+cis/lis (\%) & $\longrightarrow$ & 75,22 & $\longrightarrow$ & 77,29 \\
\hline $\mathrm{CV}(\%)$ & 2,77 & 3,58 & & \\
\hline \multicolumn{5}{|c|}{ A,B Letras diferentes na mesma linha indicam que existe diferença significativa, dentro de cada parâmetro, a 5\% de significância , pelo teste " $T$ " } \\
\hline \multicolumn{5}{|c|}{ * Médias com asterisco diferem $(\mathrm{P}<0,05)$ do Controle $(+)$ pelo teste de Dunnett. } \\
\hline \multicolumn{5}{|c|}{${ }^{1}$ Não significativo. } \\
\hline \multicolumn{5}{|c|}{${ }^{2}$ Efeito quadrático: $\mathrm{Y}=-31,845+1,71855 \mathrm{X}-0,0114234 \mathrm{X}^{2} ; \mathrm{R}^{2}=0,85(\mathrm{P}<0,04)$} \\
\hline \multicolumn{5}{|c|}{${ }^{3}$ Efeito quadrático: $\mathrm{Y}=-20,5922+1,15658 \mathrm{X}-0,00748255 \mathrm{X}^{2} ; \mathrm{R}^{2}=0,95(\mathrm{P}<0,05)$} \\
\hline
\end{tabular}

Esta maior exigência, em relação àquelas obtidas na avaliação de desempenho, pode ser explicada por Fischer (1994), que afirma que os efeitos do incremento progressivo dos níveis de aminoácidos dietéticos, nas aves, seguem a seguinte hierarquia: exigência para máximo crescimento, exigência para melhor conversão alimentar, exigência para melhor carcaça, com menos gordura, exigência para ótima composição de carcaça e exigência para maior percentagem de peito.

Estes resultados sobre os parâmetros de rendimento das fêmeas corroboram os achados por Junior et al. (2006), com frangos de corte Ross, de 22 a 42 dias de idade, os quais também verificaram efeito linear dos níveis de metionina + cistina digestível sobre os parâmetros de rendimento de carcaça e de gordura abdominal, embora não apresentando efeito sobre rendimento de peito.

\section{CONCLUSÕES}

As relações metionina + cistina/lisina digestível, para máximo desempenho de frangos de corte, machos e fêmeas, respectivamente, são de 75,53 e 78,23\%, para a fase de 11 a 21 dias, e 78,83 e 79,82\%, para a fase de 22 a 35 dias. 


\section{REFERÊNCIAS}

Albino LFT, Silva SHM, Vargas JGV, Rostagno HS \& Silva MA (1999) Níveis de metionina + cistina para frangos de corte de 1 a 21 e 22 a 42 dias de idade. Revista Brasileira de Zootecnia, 28:519-525.

Atencio AT, Albino LFT, Rostagno HS \& Vieites FM (2004) Exigências de Metionina + Cistina para Frangos de Corte Machos em Diferentes Fases de Criação. Revista Brasileira de Zootecnia, 33:1152-1166.

Baker DH \& Han Y (1994) Ideal amino acid profile for chicks during the first three weeks posthatching. Poultry Science, 73:1441-1447.

COBB (2003) Cobb Broiler Nutrition Guide. Disponínel em: <http:/

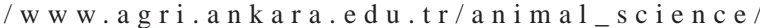
10068_Cobb_broyler_besleme_kilavuzu.pdf>. Acessado em: 01 de junho de 2012.

COBB (2005) Cobb Guía de Manejo de Pollo de engorde. Disponível em: <http://www.pronavicola.com/manuales/ ManualdeCobb.pdf>. Acessado em: 01 de junho de 2012.

Corzo A (2004) Requerimiento de lisina y perfil de aminoácidos ideal para pollos de engorde de 42 a 56 días de edad. AminoNewsTM Degussa, 5:1-10.

Fischer C (1994) The impact of amino acids on carcass quality in broilers. In: Degussa Technical Symposium \& Arkansas Nutrition Conference, Faytteville. Proceeding, Faytteville. p.14-16.

Hickling D, Guenter W \& Jackson ME (1990) The effects of dietary methionine and lysine on broiler chicken performance and breast meat yield. Canadian Journal of Animal Science, 70:673-678.

Holsheimer JP \& Veerkamp CH (1992) Effect of dietary energy, protein, and lysine content on performance and yields of two strains of male broiler chicks. Poultry Science, 71:872-879.

Huyghebaert G (1993) Comparison of DL-methionine and methionine hydroxy analogue - free acid in broilers by using multi-exponential regression model. British Poultry Science, $34: 351-359$

Junior ASV, Costa FGP \& Barros LR (2005) Níveis de Metionina + Cistina para Frangos de Corte nos Períodos de 22 a 42 e de 43 a 49 Dias de Idade. Revista Brasileira de Zootecnia, 34:1195-1201.

Junior SRG, Lana QRG, Rabello BC, Lana VSR \& Barboza AW (2006) Exigências de metionina + cistina para frangos de corte fêmeas de 1 a 21 e de 22 a 42 dias de idade criados em região de clima tropical. Revista Brasileira de Zootecnia, 35:497-503.

Mack S, Bercovici G, De Groote B, Leclercq M, Lippens M, Pack JB, Schutte YS \& Van C (1999) Ideal amino acid profile and dietary lysine specification for broiler chickens of 20 to 40 days of age. British Poultry Science, 40:257-265.

Moran Jr ET \& Bilgili SF (1990) Processing losses, carcass quality and meat yields for broiler chicken, receiving diets marginally deficient to adequate in lysine prior to marketing. Poultry Science, 69:702-710

Parsons CM \& Baker DH (1994) The concept and use of ideal proteins in feeding of non ruminants. In: Simpósio Internacional de Produção de Não Ruminantes, Maringá. Anais, Sociedade Brasileira de Zootecnia. p.119-128.

Rodrigueiro RJB, Albino LFT \& Rostagno HS (2000) Exigência de metionina + cistina para frangos de corte na fase de crescimento e acabamento. Revista Brasileira de Zootecnia, 29:507-517.

Rostagno HS, Albino LFT, Donzele JL, Gomes PC, Oliveira RF Lopes DC, Ferreira AS \& Barreto SLT (2005) Tabelas Brasileiras para Aves e Suínos - Composicão de alimentos e exigências nutricionais. Viçosa, UFV. 186p.
Rostagno HS, Albino LFT, Donzele JL, Gomes PC, Oliveira RF, Lopes DC, Ferreira AS, Barreto SLT \& Euclides RF (2011) Tabelas Brasileiras para Aves e Suínos - Composição de alimentos e exigências nutricionais. Viçosa, UFV. 252p.

SAEG (2007) Sistema para Análises Estatísticas e Genéticas. Versão 9.1. Viçosa, Universidade Federal de Viçosa. CD-ROM.

Schutte JB \& Pack M (1995) Sulfur amino acid requirement of broiler chicken from fourteen to thirty-eight days of age Performance and carcass yield. Poultry Science, 74:480-87. 